This document is the accepted manuscript version of the following article:

Duchêne, L., Kühne1, R. S., Stilp, E., Cuervo Reyes, E., Remhof, A., Hagemann, H., \&

Battaglia, C. (2017). A stable $3 \mathrm{~V}$ al1-solid-state sodium-ion battery based on a closo-borate

electrolyte. Energy and Environmental Science, 10(12), 2609-2615. https://doi.org/10.1039/

C7EE02420G

\title{
A stable $3 \mathrm{~V}$ all-solid-state sodium-ion battery based on a closo-borate electrolyte
}

\author{
L. Duchêne ${ }^{a, b}$, R.-S. Kühnel ${ }^{a}$, E. Stilp ${ }^{\text {a }}$, E. Cuervo Reyes ${ }^{a}$, A. Remhof ${ }^{a^{\dagger}}$, H. Hagemann $^{b}$ and C. \\ Battaglia \\ a. Empa, Swiss Federal Laboratories for Materials Science and Technology, CH-8600 Dübendorf, \\ Switzerland \\ b. Département de Chimie-Physique, Université de Genève, $\mathrm{CH}-1211$ Geneva 4, Switzerland. \\ † arndt.remhof@empa.ch \\ We report on a particularly stable $3 \mathrm{~V}$ all-solid-state sodium-ion battery built using a closo-borate based electrolyte, \\ namely $\mathrm{Na}_{2}\left(\mathrm{~B}_{12} \mathrm{H}_{12}\right)_{0.5}\left(\mathrm{~B}_{10} \mathrm{H}_{10}\right)_{0.5}$. Battery performance is enhanced through the creation of an intimate cathode- \\ electrolyte interface resulting in reversible and stable cycling with a capacity of $85 \mathrm{mAh} \mathrm{g}^{-1}$ at $\mathrm{C} / 20$ and $80 \mathrm{mAh} \mathrm{g}^{-1}$ \\ at $\mathrm{C} / 5$ with more than $90 \%$ capacity retention after 20 cycles at $\mathrm{C} / 20$ and $85 \%$ after 250 cycles at $\mathrm{C} / 5$. We also \\ discuss the effect of cycling outside the electrochemical stability window and show that electrolyte decomposition \\ leads to faster though not critical capacity fading. Our results demonstrate that owing to their high stability and \\ conductivity closo-borate based electrolytes could play a significant role in the development of a competitive all- \\ solid-state sodium-ion battery technology.
}

\section{Broader Context}

Rechargeable all-solid-state batteries promise higher energy density and improved operational safety. While several classes of solid-state electrolytes with high ionic conductivity have been identified over recent years, compatibility issues between electrodes and the solid-state electrolyte render their integration into a full battery cell challenging.

Here we report the successful integration of a mixed-ion sodium closo-borate electrolyte into a stable $3 \mathrm{~V}$ battery consisting of a sodium metal anode and a $\mathrm{NaCrO}_{2}$ cathode. An innovative solution-based interface engineering method was implemented to create a stable contact between cathode material and solidstate electrolyte, which is crucial for high cycling stability. With their high thermal and electrochemical stability, low toxicity, and non-flammability, our study demonstrates the high potential of closo-borate electrolytes for all-solid-state batteries.

\section{Introduction \\ https://www.dora.lib4ri.ch/empa/islandora/obje ct/empa\%3A15648}

Rechargeable lithium-ion batteries are the most important mobile energy storage technology enabling today's widespread use of portable electronics and holding strong promises for large scale deployment of electric mobility. ${ }^{1}$ However, facing an increasing demand for high performance energy storage devices, current lithium-ion batteries are challenged by safety concerns inherent to the use of flammable organic liquid electrolytes and by the rising cost of raw materials such that strong efforts are directed towards the development of batteries beyond current lithium-ion technology. ${ }^{2}$ In particular, both sodium-ion and all-solid-state batteries are intensively studied alternatives ${ }^{3,4}$ as they promise lower cost and higher safety, respectively, than current lithium-ion batteries.

Solid-state sodium-ion batteries could combine both advantages but also the challenges inherent to each technology. Our research has recently focused on answering the challenges of solid-state electrolytes and in that regard, we have recently reported ${ }^{5}$ the discovery of a closo-borate sodium superionic conductor, namely $\mathrm{Na}_{2}\left(\mathrm{~B}_{12} \mathrm{H}_{12}\right)_{0.5}\left(\mathrm{~B}_{10} \mathrm{H}_{10}\right)_{0.5}$ combining high $\mathrm{Na}^{+}$ conductivity of $0.9 \mathrm{mS} \mathrm{cm}^{-1}$ at $20^{\circ} \mathrm{C}$ with an excellent thermal stability up to at least $300^{\circ} \mathrm{C}$, and a large electrochemical stability window of $3 \mathrm{~V}$, all pre-requisites for a high performance all-solid-state sodium-ion battery.

Yet, having a highly conducting, stable solid-state electrolyte is necessary but not sufficient to build a high performance solidstate battery. Specifically, the cyclability and rate performance of solid-state batteries are strongly dependent on the quality of the contact between the electrolyte and the active materials, even more so than in liquid electrolyte based cell. ${ }^{6}$ Among the most studied solid electrolyte materials classes, sulfide phases and related chalcogenides and thiophosphates, although exhibiting high ionic conductivities, ${ }^{7-11}$ possess relatively small electrochemical stability windows ${ }^{12}$ typically below $1 \mathrm{~V}$ such that the electrolyte reacts in contact with the electrode materials. This leads to an increased electrode-electrolyte interface resistance, degrading battery performance. ${ }^{13}$ Oxidebased electrolytes are electrochemically more stable, but are hard ceramic materials that are difficult to contact with the electrode materials without high temperature sintering. ${ }^{14}$ In both cases, strategies to improve the electrode-electrolyte contact have been implemented such as the use of hybrid ceramic-polymer electrolytes, ${ }^{15}$ the insertion of a soft interlayer, ${ }^{16}$ or by directly infiltrating the cathode with solutionprocessable sulfide electrolytes. ${ }^{10,17}$ In the case of metal closoborates $M_{2} B_{n} H_{n}$ and related metal carborates $M_{C B} B_{n-1} H_{n}$, their high electrochemical stability and mechanical properties (high density pellets can be prepared by cold pressing the powders) are great advantages to build high performance batteries. However, so far only preliminary battery cycling below $3 \mathrm{~V}$ and suffering from substantial capacity fading has been reported for these materials using $\mathrm{TiS}_{2}$ as the cathode. ${ }^{18,19}$

Here we report on the first successful realization of a stable $3 \mathrm{~V}$ all-solid-state sodium-ion battery using a closo-borate based electrolyte, in combination with a sodium metal anode and a $\mathrm{NaCrO}_{2}$ based cathode. We show that by improving the solidsolid interface between the electrolyte and the cathode, $\mathrm{Na}_{2}\left(\mathrm{~B}_{12} \mathrm{H}_{12}\right)_{0.5}\left(\mathrm{~B}_{10} \mathrm{H}_{10}\right)_{0.5}$ can sustain stable and efficient cycling up to a voltage of $3.25 \mathrm{~V}$ with a reversible capacity of $85 \mathrm{mAh} \mathrm{g-}$ 
1 at a rate of $C / 20$. We also demonstrate excellent capacity retention of $85 \%$ after 250 cycles at $\mathrm{C} / 5$ and further discuss the stability of the material towards higher voltages.

\section{Device architecture \& assembly}

Figure 1a shows a scanning electron microscopy (SEM) crosssection of the pellet constituting the battery (sodium metal anode not shown), along with a schematics describing the device components. The batteries built for this study consist of sodium metal as the anode, a closo-borate based electrolyte, $\mathrm{Na}_{2}\left(\mathrm{~B}_{12} \mathrm{H}_{12}\right)_{0.5}\left(\mathrm{~B}_{10} \mathrm{H}_{10}\right)_{0.5}$, and a cathode mixture whose active material is $\mathrm{NaCrO}_{2}$. The choice of sodium metal as the anode and $\mathrm{NaCrO}_{2}$ as the cathode active material is based on the measured electrochemical stability window of $\mathrm{Na}_{2}\left(\mathrm{~B}_{12} \mathrm{H}_{12}\right)_{0.5}\left(\mathrm{~B}_{10} \mathrm{H}_{10}\right)_{0.5}$. The electrolyte is stable between 0 and approximately $3 \mathrm{~V}$ vs. $\mathrm{Na} / \mathrm{Na}^{+}$with a demonstrated cycling stability against sodium metal. ${ }^{5} \mathrm{NaCrO}_{2}$ has a theoretical capacity of $120 \mathrm{mAh} \mathrm{g}^{-1}$ and was shown ${ }^{20}$ to have a practical reversible capacity around $110 \mathrm{mAh} \mathrm{g}^{-1}$ when cycled between 2 and $3.6 \mathrm{~V}\left(\mathrm{Na}_{1-\mathrm{x}} \mathrm{CrO}_{2}, 0<\mathrm{x}<0.5\right)$ with a plateau around $3 \mathrm{~V}$ near the upper stability limit of $\mathrm{Na}_{2}\left(\mathrm{~B}_{12} \mathrm{H}_{12}\right)_{0.5}\left(\mathrm{~B}_{10} \mathrm{H}_{10}\right)_{0.5}$. In addition, $\mathrm{NaCrO}_{2}$ undergoes a relatively small volume expansion when cycled between the sodiated $\mathrm{O} 3$ structure ${ }^{21}\left(\mathrm{NaCrO}_{2}, \mathrm{R}-3 \mathrm{~m}\right.$ $V_{\text {formula-unit }}=40.75 \AA^{3}$ ) and the partially de-sodiated $\mathrm{P} 3$ structure $\mathrm{s}^{22}$ $\left(\mathrm{Na}_{0.4} \mathrm{CrO}_{2}, \mathrm{C} 2 / \mathrm{m} \mathrm{V}_{\text {formula-unit }}=40.85 \AA^{3}\right)$.

To confirm our choice we performed cyclic voltammetry on a $\mathrm{Na}\left|\mathrm{Na}_{2}\left(\mathrm{~B}_{12} \mathrm{H}_{12}\right)_{0.5}\left(\mathrm{~B}_{10} \mathrm{H}_{10}\right)_{0.5}\right| \mathrm{NaCrO}_{2}$ cell at a scan rate of $0.023 \mathrm{mV} \mathrm{s}^{-1}(\sim \mathrm{C} / 20)$. Figure $1 \mathrm{~b}$ shows the measured redox currents of $\mathrm{NaCrO}_{2}$ upon charge and discharge. The color

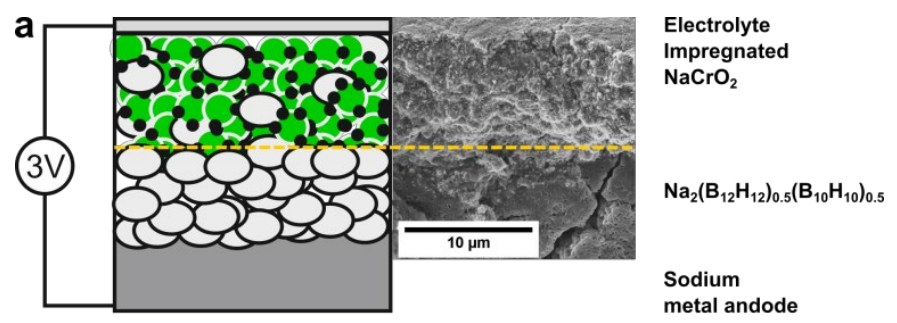

b

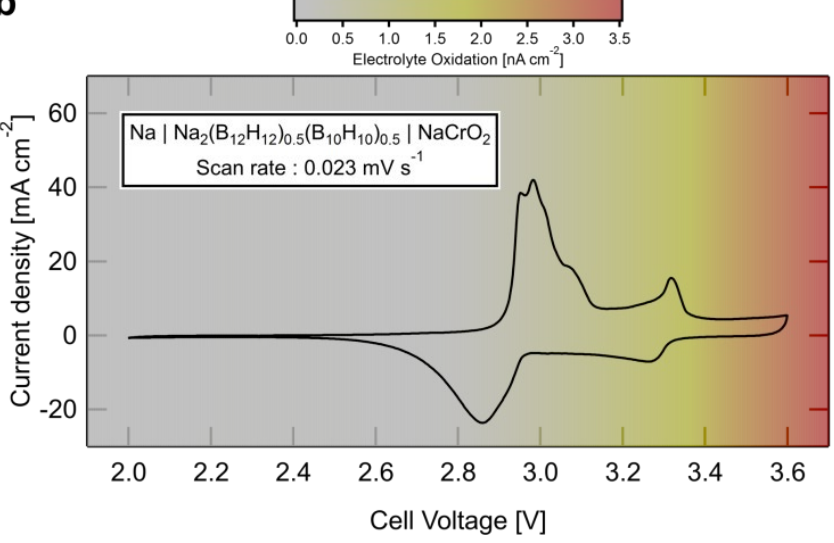

Figure 1 (a) Schematic and SEM cross section of the device investigated in this study showing the different components of the cell. (b) Cyclic voltammetry of a $\mathrm{Na}\left|\mathrm{Na}_{2}\left(\mathrm{~B}_{12} \mathrm{H}_{12}\right)_{0.5}\left(\mathrm{~B}_{10} \mathrm{H}_{10}\right)_{0.5}\right| \mathrm{NaCrO}_{2}$ cell performed at a scan rate of $0.023 \mathrm{mV} \mathrm{s}^{-1}$ at $60{ }^{\circ} \mathrm{C}$ plotted against the electrolyte oxidation currents represented by the colour gradient, observed in a cyclic voltammetry test of a $\mathrm{Na}\left|\mathrm{Na}_{2}\left(\mathrm{~B}_{12} \mathrm{H}_{12}\right)_{0.5}\left(\mathrm{~B}_{10} \mathrm{H}_{10}\right)_{0.5}\right| \mathrm{Pt}$ cell (from ref. ${ }^{5}$ ). gradient represents the oxidation current intensity measured previously for $\mathrm{Na}_{2}\left(\mathrm{~B}_{12} \mathrm{H}_{12}\right)_{0.5}\left(\mathrm{~B}_{10} \mathrm{H}_{10}\right)_{0.5 .}{ }^{5}$ Most electrochemical activity in $\mathrm{NaCrO}_{2}$ occurs around $3 \mathrm{~V}$ along with another redox reaction at higher voltages, above $3.3 \mathrm{~V}$. The results confirm that most of the electrochemical activity of $\mathrm{NaCrO}_{2}$ remains within the stability region of our electrolyte with only a minor fraction of the capacity accessible at higher voltages. The consequences of accessing this additional capacity at higher voltages will be discussed later in the paper.

$\mathrm{NaCrO}_{2}$ was prepared following a modified solid-state reaction route ${ }^{20}$ in which the intimate mixing of the $\mathrm{Cr}_{2} \mathrm{O}_{3}$ (Fluka, >99\%) and $\mathrm{Na}_{2} \mathrm{CO}_{3}$ (Alfa Aesar, ACS primary standard, 99.95\%$100.05 \%$, dried basis) precursor materials was achieved by mechanical ball-milling (2x 15 min in a Spex 8000M shaker mill, 30:1 ball-to-sample mass ratio in a tungsten carbide vial). The mixture was subsequently heat treated at $900{ }^{\circ} \mathrm{C}$ for $5 \mathrm{~h}$ in argon without the need of pressing a pellet. The resulting material shows high phase purity. No impurities were detected by X-ray diffraction (XRD) as shown in Figure 2a. The size of the corresponding $\mathrm{NaCrO}_{2}$ primary particles was determined to be between 200 to $400 \mathrm{~nm}$ by SEM, shown in Figure 2b. The electrolyte was prepared following the same procedure described in our previous study. ${ }^{5}$ Dry $\mathrm{Na}_{2} \mathrm{~B}_{12} \mathrm{H}_{12}$ and $\mathrm{Na}_{2} \mathrm{~B}_{10} \mathrm{H}_{10}$ (purchased from Katchem) were mixed by mechanical ballmilling in an equimolar ratio ( $3 \times 15 \mathrm{~min}$ in a Spex 8000M shaker mill, 10:1 ball-to-sample mass ratio in a hardened steel vial) and heat treated at $270{ }^{\circ} \mathrm{C}$ for $12 \mathrm{~h}$ in vacuum $\left(10^{-3} \mathrm{mbar}\right)$.

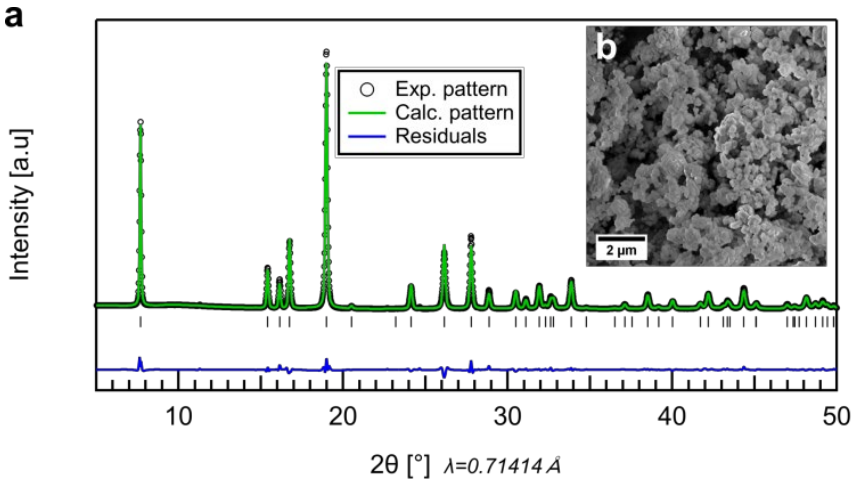

Figure 2 (a) Rietveld refinement of the XRD pattern of as synthesized $\mathrm{NaCrO}_{2}$, (b) the inset shows SEM image of the agglomerated primary cathode particles. 
Subsequently, the cathode mixture was prepared in two different ways. In a first batch, the active material, the electrolyte, and conducting carbon additive (Super-P, Timcal) were mixed in a 70:20:10 mass ratio. Mixing was done by hand in a mortar for 15 minutes to ensure homogeneous mixing. The cathode mixture prepared in this way will be further referred to as mixed cathode. We also prepared a second batch further referred to as impregnated cathode which contained the same overall 70:20:10 mass ratio of materials. However, in this case half the $\mathrm{Na}_{2}\left(\mathrm{~B}_{12} \mathrm{H}_{12}\right)_{0.5}\left(\mathrm{~B}_{10} \mathrm{H}_{10}\right)_{0.5}$ electrolyte (10 wt\% of the total cathode mixture) was first coated onto the cathode particles. This was accomplished by dissolving the electrolyte in anhydrous methanol and dispersing $\mathrm{NaCrO}_{2}$ into the solution. The mixture was then dried in vacuum and heat treated at $270{ }^{\circ} \mathrm{C}$ in order to recrystallize the electrolyte. Finally the remaining $10 \mathrm{wt} \%$ of the electrolyte and the $10 \mathrm{wt} \%$ carbon additive were added and all three components were grinded together for $15 \mathrm{~min}$ analogously to the mixed cathode.

To assemble the battery, $2 \mathrm{mg}$ of the cathode mixture $(1.4 \mathrm{mg}$ active material) and $80 \mathrm{mg}$ of electrolyte were pressed together under a pressure of $900 \mathrm{MPa}$ to form a $500 \mu \mathrm{m}$ thick pellet with a diameter of $12 \mathrm{~mm}$. The sodium metal anode was prepared from a block of sodium metal rolled into a thin foil and punched into a $12 \mathrm{~mm}$ disc. The components of the cell were then assembled together in a Swagelok type cell in a two-electrode configuration.

\section{Device characterization}

Figure $3 a$ and $b$ show the results of the cycling of cells built with the mixed and impregnated cathode, with a current of $6 \mathrm{~mA} \mathrm{~g}^{-1}$ ( $C / 20$ assuming a theoretical capacity of $120 \mathrm{mAh} \mathrm{g}^{-1}$ ). Upon charging, the voltage was cut at $3.25 \mathrm{~V}$, below the $3.6 \mathrm{~V}$ normally used for $\mathrm{NaCrO}_{2}$, to minimize electrolyte decomposition at voltages outside its stability window (see again Figure $1 \mathrm{~b}$ ). Still, strong capacity fading was observed in the cell using the mixed cathode. Already the initial discharge capacity is below $60 \mathrm{mAh} \mathrm{g}^{-1}$ although the first charge capacity is close to $100 \mathrm{mAh} \mathrm{g}^{-1}$. By the time the cell efficiency reaches values above $90 \%$ ( $3^{\text {rd }}$ cycle) the discharge capacity already falls below $35 \mathrm{mAh} \mathrm{g}^{-1}$ and drops to $9.5 \mathrm{mAh} \mathrm{g}^{-1}$ after 20 cycles. In the case of the impregnated cathode, the cell shows much better capacity retention already at the first cycle with an initial charge and discharge capacity of $99 \mathrm{mAh} \mathrm{g}^{-1}$ and $88 \mathrm{mAh} \mathrm{g}^{-1}$, respectively, i.e. a coulombic efficiency of $89 \%$ which quickly increases to values above $99 \%$ upon further cycling. Importantly, the cell retained $94.6 \%$ of the initial discharge capacity after 20 cycles at $\mathrm{C} / 20$. Rate tests also shown in Figure $3 \mathrm{~b}$ indicate that the cell using the impregnated cathode can be cycled at up to $\mathrm{C} / 5$ with very little capacity loss. Longer term stability was assessed by cycling a second cell at $\mathrm{C} / 5$ for 250 cycles (two months cycling) after activation with 3 cycles at $\mathrm{C} / 20$. The cell retained $85 \%$ of the initial discharge capacity with a coulombic efficiency greater than $99.5 \%$ (see figure $3 c$ ) thereby confirming the high stability of the system.

Internal cell short-circuits due to metallic sodium deposits at grain boundaries and in cracks of our solid-state electrolyte,
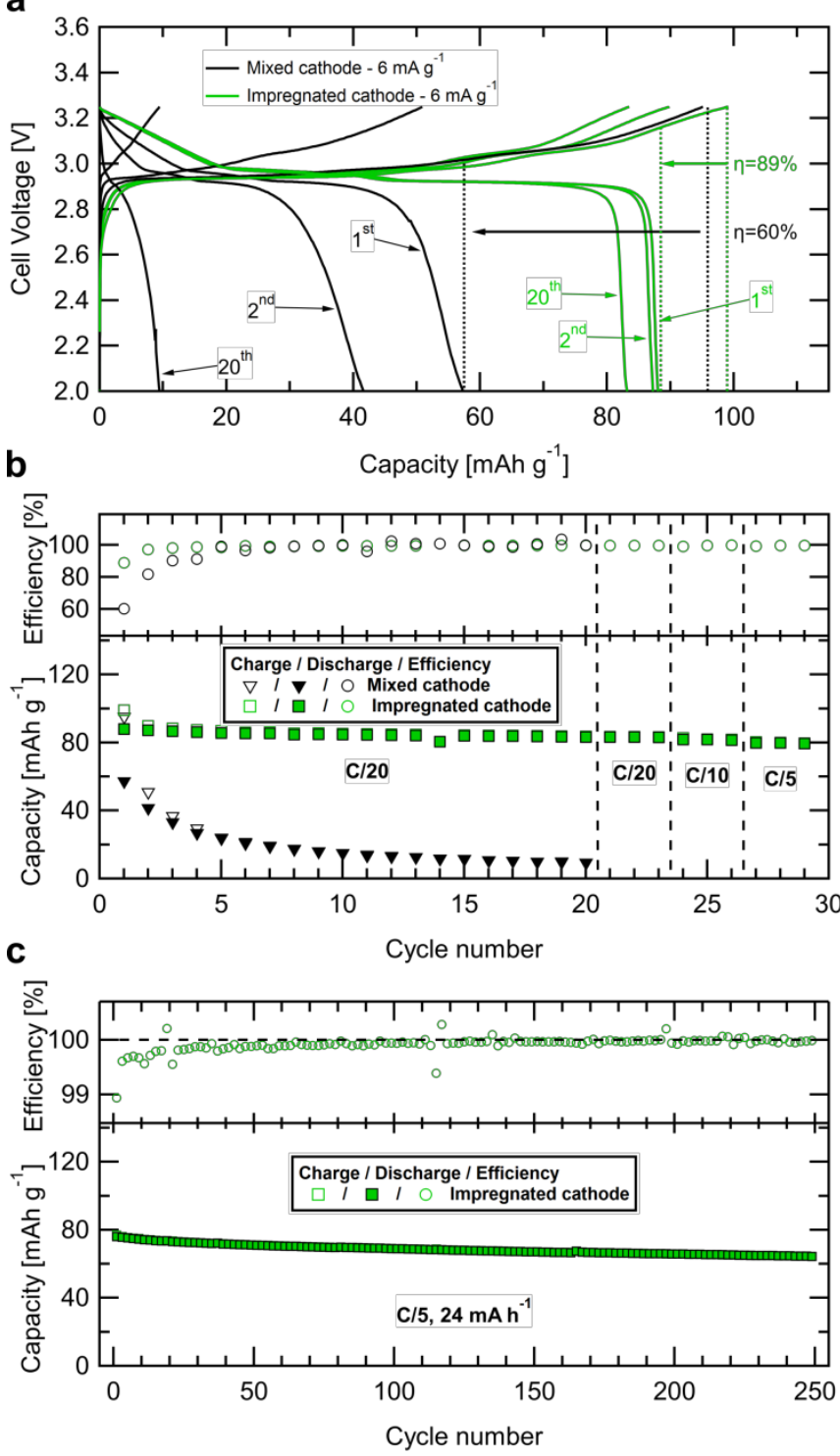

Figure 3 (a) Charge/discharge profiles for the $1^{\text {st }}, 2^{\text {nd }}$ and $20^{\text {th }}$ cycle of $\mathrm{Na}\left|\mathrm{Na}_{2}\left(\mathrm{~B}_{12} \mathrm{H}_{12}\right)_{0.5}\left(\mathrm{~B}_{10} \mathrm{H}_{10}\right)_{0.5}\right| \mathrm{NaCrO}_{2}$ cells with mixed and impregnated cathode mixtures. (b) Electrochemical cycling stability and coulombic efficiencies for the same cells. For the impregnated cathode the rate performance up to $\mathrm{C} / 5$ is also presented. (c) Long term cycling of a cell using the impregnated cathode. The cell was initially activated by 3 charge/discharge cycles at $C / 20$ and subsequently cycled 250 times at $C / 5$. Charge and discharge capacity and efficiency are shown every 2 cycles.

analogous to the formation of dendrites in liquid electrolyte cells, could be prevented by operating the cells at a slightly elevated temperature of $60^{\circ} \mathrm{C}$. At this temperature closer to the melting temperature of sodium at $98{ }^{\circ} \mathrm{C}$, the critical current density at which failure by sodium penetration may occur increases. ${ }^{23}$ Although $\mathrm{Na}_{2}\left(\mathrm{~B}_{12} \mathrm{H}_{12}\right)_{0.5}\left(\mathrm{~B}_{10} \mathrm{H}_{10}\right)_{0.5}$ can be coldpressed into dense pellets ( $>90 \%$ of the theoretical density) and shows no significant grain boundary resistance, ${ }^{5}$ SEM images reveal the presence of occasional cracks in the pellet. Sodium deposits at such defects can lead to current concentration at the crack tip and ultimately metal penetration through the electrolyte, even in very hard materials. ${ }^{24,25}$ In the future, formation of such deposits at room temperature may be solved by interface engineering on the anode side, e.g. by the addition 
of a defect free interlayer improving the metal wetting on the electrolyte surface. ${ }^{26}$

Our cycling results suggest that the capacity fading observed in the cell using the mixed cathode is not due to electrolyte decomposition but rather to an electrode-electrolyte contact loss between the electrode and the electrolyte. To qualitatively analyze the contact quality in the two cathode composites, we recorded SEM images of the cathode particles embedded in the electrolyte, as seen on the battery pellet surface. The images for the mixed and impregnated cathode are shown in Figure 4a and $b$, respectively. In both cases, the different components can be clearly identified from their morphology and contrast arising from the different electronic conductivities. At high magnification, numerous cracks in the $1-10 \mu \mathrm{m}$ range can be observed, mainly concentrated around the $\mathrm{NaCrO}_{2}$ particles in the mixed cathode whereas the particles are smoothly embedded in the electrolyte in the impregnated cathode. In the latter case, the good contact between $\mathrm{NaCrO}_{2}$ and $\mathrm{Na}_{2}\left(\mathrm{~B}_{12} \mathrm{H}_{12}\right)_{0.5}\left(\mathrm{~B}_{10} \mathrm{H}_{10}\right)_{0.5}$ makes sodium ions easily available to single cathode particles upon charge and discharge, while the additional electrolyte provides contact between the different particles, and the carbon ensures electric contact throughout the electrode. Also, we would like to stress that our synthesis of $\mathrm{NaCrO}_{2}$ yields relatively small particle sizes, thereby increasing the contact surface area with the electrolyte which can be beneficial to the overall battery performance. ${ }^{27}$

To quantitatively analyze the evolution of the cathodeelectrolyte contact upon cycling, we performed electrochemical impedance spectroscopy on two cells with the mixed and impregnated cathode, respectively. Both cells were cycled at $\mathrm{C} / 20$ and impedance was measured in the fully charged state after $30 \mathrm{~min}$ relaxation at open-circuit. The resulting Nyquist plot are displayed for selected cycles in the inset of Fig. 4c, while the real part of the impedance is replotted vs frequency in the main figure. The impedance of the cell with impregnated cathode remains roughly an order of magnitude smaller compared to the impedance of the cell with mixed cathode. In particular, the mid-frequency contribution corresponding to the visible semi-circle in the Nyquist plot shows the strongest evolution. For the cell with the mixed cathode we observe a factor 10 increase of the impedance, from $100 \Omega$ to $1 \mathrm{k} \Omega$ as the cell is cycled. The increase is much less pronounced for the impregnated cathode as the impedance increases from 50 to only $125 \Omega$ after 10 cycles. This is accompanied by a slight frequency dependence of the impedance at high frequencies $>10^{4} \mathrm{~Hz}$ for the mixed cathode, resulting from the onset of a second semi-circle visible in the Nyquist plot, which has been previously attributed to electrode-current collector contact contribution. ${ }^{28}$ This effect is not seen for the impregnated cathode indicating a better contact to the current collector. Finally, also the low frequency contribution to the impedance is much smaller for the impregnated cathode reflecting the improved charge transport in the bulk of the cathodeelectrolyte composite bulk due to the better contact obtained by impregnation. In summary, impedance measurements demonstrate that the different impedance contributions in the cells are lower for the impregnated cathode than for the mixed
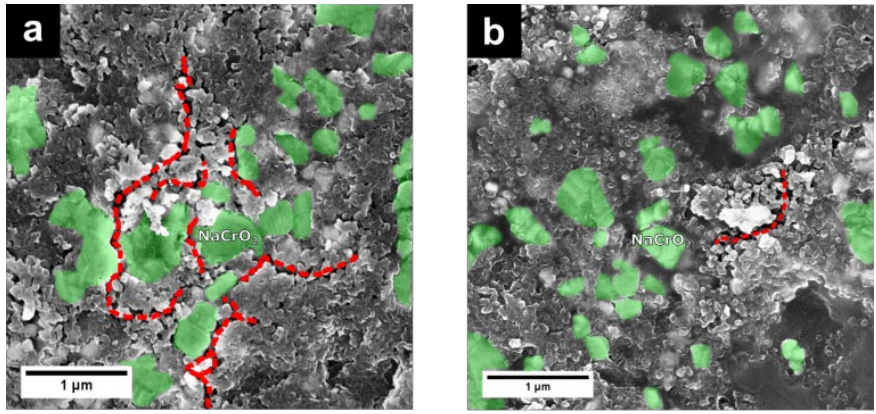

C

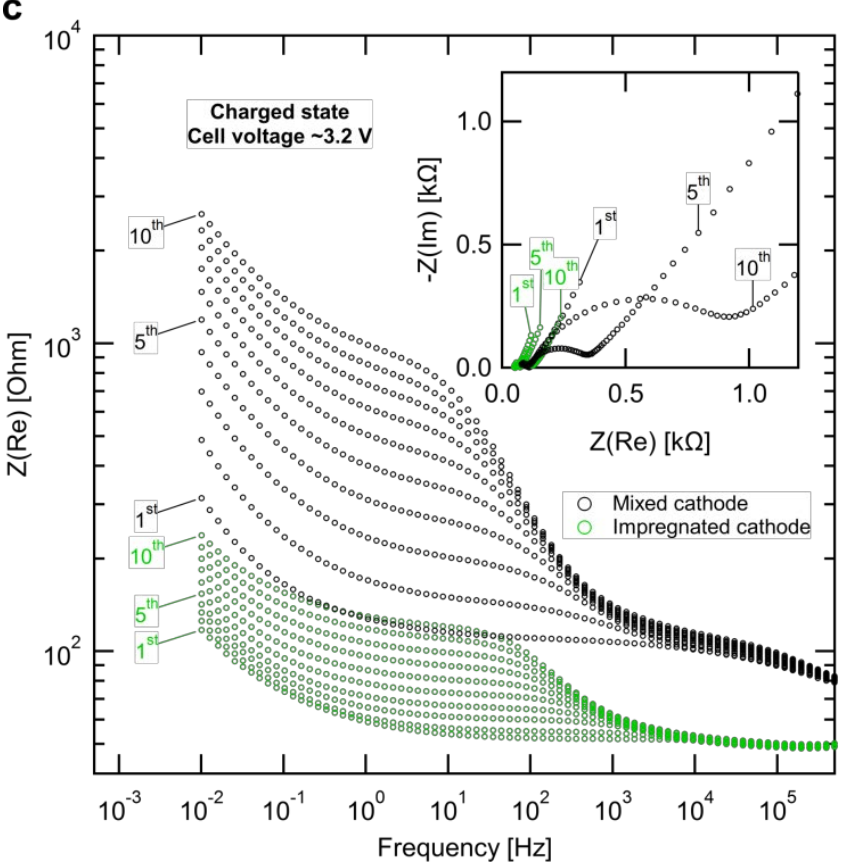

Figure 4 (a-b) Top-view SEM images of the (a) mixed and (b) impregnated cathode mixtures after pressing into a pellet. Cathode particles and cracks are highlighted by green areas and red lines, respectively. (c) Real part of the impedance plotted versus frequency measured after each charge plus relaxation cycle of cells using the mixed and impregnated cathode, respectively. Corresponding Nyquist plots for cycles 1, 5 and 10 are given as an inset.

cathode and that this improvement remains stable upon cycling. Since both cells only differ in the electrode-electrolyte contacting method, these results indicate that the intimate cathode-electrolyte contact created upon solvent impregnation is instrumental for avoiding additional impedance build-up from electrode-electrolyte contact loss (and a small contribution from contact to the current-collector) during cycling, enabling long-term stability.

Our results are in line with a solvent-based method recently reported by Banerjee et al. ${ }^{10}$ for the sodium solid-state electrolyte $\mathrm{Na}_{3} \mathrm{SbS}_{4}$, also using $\mathrm{NaCrO}_{2}$ as the cathode. In their study, it is shown that as a result of the solution process the electrolyte is creating a partial thin coating around the cathode particles. Our cell cycling and impedance data support the use of solution impregnation as a means to create intimate electrode-electrolyte contact. This method is also particularly interesting for upscaling electrode fabrication as demonstrated recently. ${ }^{17}$ In this prospect, further optimization of the ratio of the cathode active material to the solid-state electrolyte has yet to be performed. In particular it has been discussed by Zhang et 
$a l .{ }^{29}$ that the exact mass loading may be adapted depending on the targeted battery application, i.e. high electrolyte mass loading in solid-state batteries is desirable for high power applications whereas lower electrolyte content should be employed to reach high energy density.

The effect of electrolyte decomposition was then assessed by cycling outside the electrochemical stability window of the electrolyte. We cycled a cell using the high performance impregnated cathode to $3.6 \mathrm{~V}$, the cut-off voltage typically applied for $\mathrm{NaCrO}_{2}$ in order to extract the maximum reversible capacity of $\mathrm{NaCrO}_{2}$. Figure 5 a shows the resulting cycling curves at the $1^{\text {st }}, 2^{\text {nd }}$ and $20^{\text {th }}$ cycles along with the first charge/discharge cycle of $\mathrm{NaCrO}_{2}$ in a liquid electrolyte based cell as measured by Komaba et al. ${ }^{20}$ Upon the first charge, the solid electrolyte cell shows similar characteristics compared to the liquid electrolyte based cell, both in terms of capacity and potentials. Only at voltages above $3.3 \mathrm{~V}$ i.e. after the last sodium ion extraction as seen in the cyclic voltammetry measurement, the charging of the solid-state cell deviates, showing additional apparent capacity where the potential of the liquid-state cell increases almost vertically to the $3.6 \mathrm{~V}$ cut-off. This behavior is typically caused by currents arising from electrolyte decomposition. This is further confirmed by the first discharge cycle. While the liquid cell retains most of the initial charge capacity, the solid-state cell shows an efficiency of only $75 \%$ on the first cycle. During the following cycles, the cell efficiency quickly increases to values close to $100 \%$, but remains always

a

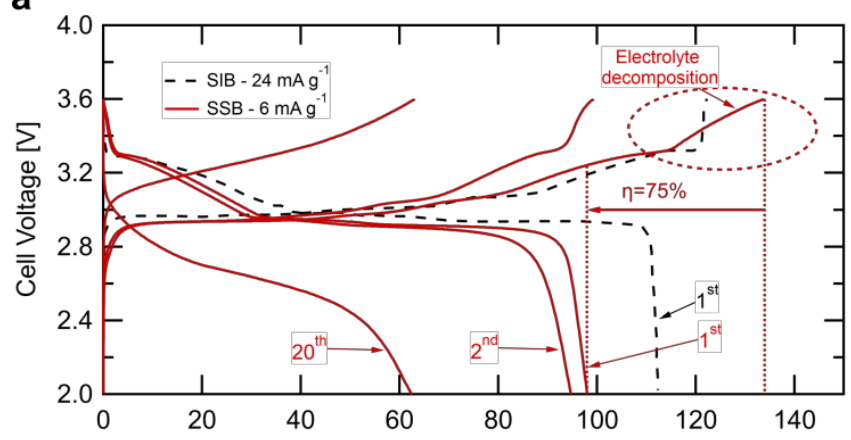

b

Capacity $\left[\mathrm{mAh} \mathrm{g}^{-1}\right]$

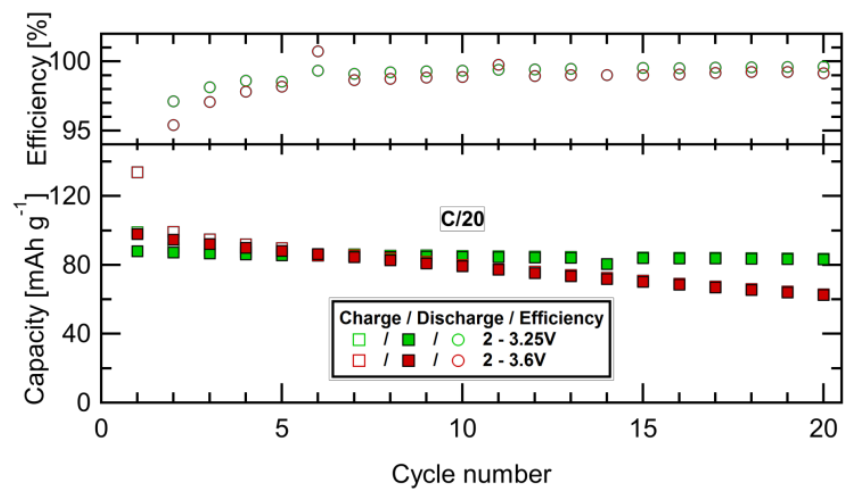

Figure 5 (a) Charge/discharge profile for the $1^{\text {st }}, 2^{\text {nd }}$ and $20^{\text {th }}$ cycles of a $\mathrm{Na}\left|\mathrm{Na}_{2}\left(\mathrm{~B}_{12} \mathrm{H}_{12}\right)_{0.5}\left(\mathrm{~B}_{10} \mathrm{H}_{10}\right)_{0.5}\right| \mathrm{NaCrO}_{2}$ solid state battery (SSB) with the impregnated cathode mixture cycled between 2 and $3.6 \mathrm{~V}$. The first charge/discharge cycle of $\mathrm{NaCrO}_{2}$ in a liquid electrolyte sodium-ion battery $(\mathrm{SIB})^{20}$ is shown for comparison. (b) Electrochemical cycling performance and coulombic efficiencies of $\mathrm{Na}\left|\mathrm{Na}_{2}\left(\mathrm{~B}_{12} \mathrm{H}_{12}\right)_{0.5}\left(\mathrm{~B}_{10} \mathrm{H}_{10}\right)_{0.5}\right| \mathrm{NaCrO}_{2}$ cells with the same impregnated cathode mixture, cycled within different voltage windows. lower than those observed for the cell cycled to $3.25 \mathrm{~V}$, as shown in Figure $5 \mathrm{~b}$. This is evidence for more pronounced electrolyte decomposition in the cell cycled to such high voltages, resulting in a steady decrease in the cells capacity. After 20 cycles, the discharge capacity drops to $62.5 \mathrm{mAh} \mathrm{g}^{-1}$, i.e. $65 \%$ of the initial capacity. The fact that most fading occurs on the first cycle hints towards a partially passivating interphase layer. Electrochemical stability of closo-borate compounds has been previously studied for salts in solution and it was shown $n^{30,31}$ that decomposition occurs through the dimerization of two anions with the release of $\mathrm{H}_{2}$, similar to their thermal decomposition behavior. ${ }^{32,33}$ We suspect a similar behavior for $\mathrm{Na}_{2}\left(\mathrm{~B}_{12} \mathrm{H}_{12}\right)_{0.5}\left(\mathrm{~B}_{10} \mathrm{H}_{10}\right)_{0.5}$ at such elevated voltage even though the exact nature of the electrochemical decomposition products of closo-borate salts in the solid state is not known at this point. Work is now in progress to understand the electrochemical stability of these compounds and their interfaces to the active materials in more details.

\section{Conclusions}

Benefitting from the high conductivity and high electrochemical stability of $\mathrm{Na}_{2}\left(\mathrm{~B}_{12} \mathrm{H}_{12}\right)_{0.5}\left(\mathrm{~B}_{10} \mathrm{H}_{10}\right)_{0.5}$, we demonstrated for the first time that this solid-state electrolyte can be used to build a stable $3 \mathrm{~V}$ solid-state sodium-ion battery. To achieve such stable cycling, improved electrode-electrolyte contact was engineered via a solution impregnation of the electrolyte onto the cathode particles. The resulting cell using a sodium metal anode and an impregnated $\mathrm{NaCrO}_{2}$ cathode mixture exhibits high cycling stability with a reversible capacity of $85 \mathrm{mAh} \mathrm{g}^{-1}$ at $\mathrm{C} / 20$ and $80 \mathrm{mAh} \mathrm{g}^{-1}$ at $\mathrm{C} / 5$ and $85 \%$ capacity retention after 250 cycles at $\mathrm{C} / 5$. As expected, the cells show faster fading when cycled to voltages outside the stability window of the electrolyte due to electrolyte decomposition. Room temperature cycling was not possible because of dendrite formation. Our results thus confirm the change of paradigm in designing solid-state batteries that is the shift in focus from conductivity improvement to interface optimization, ${ }^{12}$ and demonstrate that closo-borate electrolytes can play a significant role in this new development strategy for high performance all-solid-state batteries.

\section{Experimental}

Materials synthesis and cell assembly: See main text.

Powder X-ray Diffraction (XRD): XRD patterns for $\mathrm{NaCrO}_{2}$, were collected at the Swiss Norwegian Beam Lines (SNBL) at the European Synchrotron research Radiation Facility (ESRF) in Grenoble, France. ${ }^{34}$ The wavelength at the time of the acquisition was $0.71414 \AA$. The 2D patterns were integrated from 3D images acquired on a PILATUS $2 \mathrm{M}$ image plate detector. Samples were sealed into glass capillaries, filled under argon atmosphere.

The refinements were performed using the Fullprof refinement software, ${ }^{35}$ based on a published structural model for $\mathrm{NaCrO}_{2} .{ }^{21}$ 
Scanning Electron Microscopy: SEM images were acquired using a FEl Strata 235 SEM at an accelerating voltage of $5 \mathrm{kV}$, and a base pressure of $1.4 \times 10^{-6}$ mbar. Cross sections were acquired by tilting the sample by $52^{\circ}$. For both the plane view and cross section images the working distance was $5 \mathrm{~mm}$.

Electrochemical measurements: Cyclic voltammetry, galvanostatic cycling, and electrochemical impedance spectroscopy were conducted using a BioLogic VMP3 multichannel potentiostat. The batteries were prepared as described in the main text and tested in a two-electrode configuration. Impedance spectroscopy was measured with a frequency ranging from $1 \mathrm{MHz}$ to $10 \mathrm{mHz}$.

\section{Conflicts of Interest}

There are no conflicts of interest to declare.

\section{Acknowledgements}

We thank lurii Dovgaliuk for his support with the XRD data acquisition at the Swiss Norwegian Beam Lines (SNBL) at the European Synchrotron research Radiation Facility (ESRF) in Grenoble, France.

We are grateful to the Swiss National Science Foundation (SNSF) for financial support within the Sinergia project 'Novel ionic conductors' under contract number CRSII2_160749/1. This works was further partially supported by the Commission for Technology and Innovation (CTI) through funding for the Swiss Competence Center for Energy Research (SCCER) Heat and Electricity Storage under contract number 1155-002545.

\section{References}

1 J.-M. Tarascon and M. Armand, Nature, 2001, 414, 359367.

2 J. W. Choi and D. Aurbach, Nat. Rev. Mater., 2016, 1, 16013.

3 D. Kundu, E. Talaie, V. Duffort and L. F. Nazar, Angew. Chemie - Int. Ed., 2015, 54, 3432-3448.

4 J. Janek and W. G. Zeier, Nat. Energy, 2016, 1, 16141.

5 L. Duchêne, R.-S. Kühnel, D. Rentsch, A. Remhof, H. Hagemann and C. Battaglia, Chem. Commun., 2017, 53, 4195-4198.

6 A. C. Luntz, J. Voss and K. Reuter, J. Phys. Chem. Lett., 2015, 6, 4599-4604.

7 A. Hayashi, K. Noi, A. Sakuda and M. Tatsumisago, Nat. Commun., 2012, 3, 856.

8 L. Zhang, K. Yang, J. Mi, L. Lu, L. Zhao, L. Wang, Y. Li and H. Zeng, Adv. Energy Mater., 2015, 5, 2-6.

9 W. D. Richards, T. Tsujimura, L. J. Miara, Y. Wang, J. C. Kim, S. P. Ong, I. Uechi, N. Suzuki and G. Ceder, Nat. Commun., 2016, 7, 11009.

10 A. Banerjee, K. H. Park, J. W. Heo, Y. J. Nam, C. K. Moon, S. M. Oh, S.-T. Hong and Y. S. Jung, Angew. Chemie Int. Ed., 2016, 55, 9634-9638.
Z. Yu, S. L. Shang, J. H. Seo, D. Wang, X. Luo, Q. Huang, S. Chen, J. Lu, X. Li, Z. K. Liu and D. Wang, Adv. Mater., 2017, 29, 0-6.

Y. Tian, T. Shi, W. D. Richards, J. Li, J. C. Kim, S. Bo and G. Ceder, Energy Environ. Sci., 2017, 10, 1150-1166.

R. Koerver, I. Aygün, T. Leichtweiss, C. Dietrich, W. Zhang, J. O. Binder, P. Hartmann, W. G. Zeier and J. Janek, Chem. Mater., 2017, 29, 5574-5582.

F. Lalère, J. B. Leriche, M. Courty, S. Boulineau, V. Viallet, C. Masquelier and V. Seznec, J. Power Sources, 2014, 247, 975-980.

J.-K. Kim, Y. J. Lim, H. Kim, G.-B. Cho and Y. Kim, Energy Environ. Sci., 2015, 8, 3589-3596.

H. Gao, L. Xue, S. Xin, K. Park and J. B. Goodenough, Angew. Chemie - Int. Ed., 2017, 5633-5637. D. H. Kim, D. Y. Oh, K. H. Park, Y. E. Choi, Y. J. Nam, H. A. Lee, S.-M. Lee and Y. S. Jung, Nano Lett., 2017, 17, 30133020.

W. S. Tang, A. Unemoto, W. Zhou, V. Stavila, M. Matsuo, H. Wu, S. Orimo and T. J. Udovic, Energy Environ. Sci., 2015, 8, 3637-3645.

K. Yoshida, T. Sato, A. Unemoto, M. Matsuo, T. Ikeshoji, T. J. Udovic and S. Orimo, Appl. Phys. Lett., 2017, 110, 103901.

S. Komaba, C. Takei, T. Nakayama, A. Ogata and N. Yabuuchi, Electrochem. commun., 2010, 12, 355-358. W. Scheld and R. Hoppe, Zeitschrift für Anorg. und Allg. Chemie, 1989, 568, 151-156.

S.-H. Bo, X. Li, A. J. Toumar and G. Ceder, Chem. Mater., 2016, 28, 1419-1429. L. C. De Jonghe, L. Feldman and A. Buechele, Solid State Ionics, 1981, 5, 267-269.

L. Porz, T. Swamy, B. W. Sheldon, D. Rettenwander, T. Frömling, H. L. Thaman, S. Berendts, R. Uecker, W. C. Carter and Y.-M. Chiang, Adv. Energy Mater., 2017, 1701003, 1701003. Y. Ren, Y. Shen, Y. Lin and C.-W. Nan, Electrochem. commun., 2015, 57, 27-30. W. Zhou, Y. Li, S. Xin and J. B. Goodenough, ACS Cent. Sci., 2017, 3, 52-57.
A. Hayashi, Y. Nishio, H. Kitaura and M. Tatsumisago, Electrochem. commun., 2008, 10, 1860-1863. M. Gaberscek, J. Moskon, B. Erjavec, R. Dominko and J. Jamnik, Electrochem. Solid-State Lett., 2008, 11, A170. W. Zhang, D. A. Weber, H. Weigand, T. Arlt, I. Manke, D. Schröder, R. Koerver, T. Leichtweiss, P. Hartmann, W. G. Zeier and J. Janek, ACS Appl. Mater. Interfaces, 2017, 9, 17835-17845.

R. L. Middaugh and F. Farha Jr., J. Am. Chem. Soc., 1966, 88, 4147-4149.

R. J. Wiersema and R. L. Middaugh, J. Am. Chem. Soc., 1967, 89, 5078-5078.

L. He, H.-W. Li and E. Akiba, Energies, 2015, 8, 1242912438.

A. Remhof, Y. Yan, D. Rentsch, A. Borgschulte, C. M. Jensen and A. Züttel, J. Mater. Chem. A, 2014, 2, 7244.

V. Dyadkin, P. Pattison, V. Dmitriev and D. Chernyshov, J. 
Synchrotron Radiat., 2016, 23, 825-829.

35 J. Rodríguez-Carvajal, Phys. B Condens. Matter, 1993, 192,

55-69. 